\title{
How the Philosophies, Styles, and Methods of Family Medicine Affect the Research Agenda
}

\author{
Allen Hutchinson, FRCGP, FFPHM ${ }^{1}$ \\ Lorne A. Becker, $M D^{2}$ \\ 'Section of Public Health, University of \\ Sheffield, Sheffield, England, UK \\ ${ }^{2}$ Department of Family Medicine, State \\ University of New York, Upstate Medical \\ University, Syracuse, NY
}

\begin{abstract}
Family physicians provide person-centered, continuous, comprehensive care that is accessible and available at the time of need. Although this core philosophy is shared around the world, its translation into actual practice can vary greatly with time and from place to place as family physicians adapt to local constraints and conditions. Factors driving these local variations include entrenched habits and patterns of care, funding systems, patient expectations, public policy, and the availability and quality of other critical health system components.

This diversity provides both an opportunity and a challenge for family medicine research. The potential for fruitful comparisons and contrasts arising from natural experiments may require investigators to use multiple research methods capable of evaluating complex interventions and comparisons.

Family medicine has the capacity to be an excellent laboratory in which research in representative populations can offer the pragmatic answers needed by practicing physicians. The nature of the research questions and interventions require the involvement of clinicians in the formulation of research questions and evaluation of the applicability of research results. The variations in implementation of the family medicine philosophy can be a potential asset because of the research opportunities they provide.
\end{abstract}

Ann Fam Med 2004;2(Suppl 2):S41-S44. DOI: 10.1370/afm.195.

\section{INTRODUCTION}

$\mathrm{H}$ ow do the philosophy, styles, methods, and tasks of family medicine affect the research agenda? To understand and answer this question, it is important first to try to understand the term family medicine and the philosophy that underpins it. Only then can we explore the challenges and opportunities offered to the research agenda through the wide range of styles and methods of family medicine.

\section{PHILOSOPHY AND STYLE OF FAMILY MEDICINE}

Conflicts of interest: none reported

The medical literature contains many thoughtful treatises on the driving philosophy of family medicine. An early review (undertaken to guide the training of British general practitioners) focused on the one-to-one doctorpatient-family relationship:

The general practitioner is a doctor who provides personal, primary and continuing medical care to individuals and families, ... his diagnoses will be composed in physical, psychological and social terms. He will intervene educationally, preventively and therapeutically to promote his patient's health. ${ }^{1}$ 


\section{Table 1. Characteristics of Family Physicians}

Are committed to the person, rather than to a particular body of knowledge, group of diseases or special technique(s)

Seek to understand the context of the illness

See every patient contact as an opportunity for prevention or health education

View the practice as a population at risk

Should ideally share the same habitat as their patients

See patients in their homes

Attach importance to the subjective aspects of medicine

Are managers of resources

Adapted from McWhinney. ${ }^{2}$

McWhinney ${ }^{2}$ enunciated a broader philosophy (Table 1), adding a population perspective and noting a societal role as a manager of scarce health resources. Olesen and colleagues, ${ }^{3}$ coming from a northwest European tradition, have attempted a definition that includes teamwork as an important part of the role, and recognize the importance of the differing circumstances in which physicians find themselves around the world (Table 2).

A basic triad ${ }^{4}$ of continuous, comprehensive care, accessible and available at the time of need, is shared by all of these descriptions (even if delivering on the promise is sometimes difficult). This construct includes first-contact care, encompasses long-term illness management, and recognizes the need to management resources effectively. ${ }^{5}$ Also commonly described is a style of patient involvement that includes patient centeredness, recognition of the context of illness, an orientation to prevention, evidence-based decision making, and a family focus.

This set of philosophies and styles is not exclusive to family medicine. Physicians who do not specialize in family medicine sometimes fill parts of the role (first-contact care by emergency physicians) or serve as primary care physicians for patients defined by specific limited criteria (some pediatricians or geriatricians). Others assume this role for a subset of their patients, particularly those with a complex health problem with implications for multiple

\section{Table 2. Suggested New Definition for General Practice}

\footnotetext{
The general practitioner is a specialist trained to work in the front line of a healthcare system and to take the initial steps to provide care for any problem(s) that patients may have. The general prac titioner takes care of individuals in a society, irrespective of the patient's type of disease or other personal and social characteristics, and organises resources available in the healthcare system to the best advantages of the patients. The general practitioner engages with autonomous individuals across the fields of prevention, diagnosis, cure, care and palliation, using and integrating the sciences of biomedicine, medical psychology and medical sociology.

From Olesen et al.
}

systems (such as patients on renal dialysis or with terminal cancer). Family medicine, however, is unique in that the above philosophy defines the entire discipline and infuses its relationships with all patients.

Do these philosophies and styles lead to better outcomes for patients? For some components, the answer appears to be yes. Starfield ${ }^{6}$ has identified 4 attributes of primary care that fit with portions of the family medicine philosophy-first contact, longitudinality, comprehensiveness, and coordination-and has developed structure and process measures for each concept. Applying these measures to large national and international data sets, she has been able to show that systems providing good support for these primary care roles enjoy better health outcomes than those that do not. ${ }^{7}$ Stewart and her colleagues have taken a similar organized approach to investigating the effectiveness of a patient-centered approach-developing and validating measures of patient centeredness that they have shown to be associated with improved health outcomes and more parsimonious use of diagnostic tests. ${ }^{8}$

Are there other components of the family medicine philosophy that can be similarly defined in operational measurable terms? What are the specific components of the primary care or patient-centered style that lead to better outcomes? How can these be strengthened and taught?

\section{TASKS AND METHODS IN FAMILY MEDICINE}

The context in which family medicine is carried out can have a huge influence on specifics of clinical and organizational practice. Different physicians and associated teams take substantially different approaches to family medicine. The contrasts can be stark and differ more in their scope and variety from those found within most other branches of medicine. Many local drivers for these differences involve not only economics and social geography but also the wider political context.

Differences between countries and changing roles within countries are clearly important and seem to be among the defining features of family medicine. Indeed, there may be considerable differences between health care systems even when there might seem to be reasonably consistent public policies. European general practice (family medicine) provides a good example.

A recent review of general practice examined the organization of care in many European health systems. ${ }^{9}$ Recurrent restructuring seemed to be a common theme as states struggled with the best way to provide firstcontact care. Community norms (and perhaps professional values) were found to vary greatly, with average consultation rates per patient in Germany at 13 per year compared with 3.3 per year in the Netherlands. The differences are even larger when systems with widely differ- 
ing basic philosophies of health care and use of resources are included. Thus family physicians in the fragmented and entrepreneurial US system may face a set of tasks different from their European colleagues. Fast-developing countries reflect diversity of a different sort. Family medicine (that is comprehensive, coordinated, and accessible) might be provided by office-based physicians who have had little training in the principles of family medicine and limited access to some of the interventions used by family physicians elsewhere. Even the evidence base for care may be different in countries where a mix of traditional health care and Western medicine is practiced. In many parts of the world, teamwork with colleagues from different professions or medical specialties is seen as essential to high-quality primary care. In other countries, however, the team may be only a solo practitioner with or without an assistant.

Public policy and public expectations shape many of these international differences. In countries where health systems allow patients open access to multiple consultations, effectively delivering 3 of Starfield's coordinates-longitudinality, comprehensiveness, and coordination-may be more problematic. ${ }^{10}$ Structural impediments also hamper efforts to care for a population at risk. Where local competition rules prohibit contacting patients to offer anticipatory care, it is difficult to translate this aspect of philosophy into practice.

Differences in health care funding can lead to additional variation. As an example, American family physicians are much less likely than their Canadian counterparts to provide psychotherapy or formal counseling for their patients. The difference is in part due to training, but American physicians are also heavily influenced by major restrictions to reimbursement for this service by their insurance companies. Family physicians who find themselves in situations in which financial structures provide a disincentive to practicing preventive medicine may find it difficult to fulfill this core role. ${ }^{11}$

Changes to physician reimbursement systems are currently being widely debated. A recent UK report ${ }^{12}$ suggests that no single form of payment system will fit the complexity of the tasks carried out by family physicians and suggests multiple types of reimbursement. A report from the US Institute of Medicine ${ }^{13}$ calls for major reforms to US health care to address the "quality chasm"; it recommends changing reimbursement systems to reflect that health care occurs not only during faceto-face visits but also increasingly by telephone, e-mail, or the Internet. While these changes may strengthen the role of family medicine, they represent yet another variable with the potential to affect the translation of the family medicine philosophy into effective care.

Reimbursement systems are not the only source of change. Many countries have seen a variety of shifts based as much on political agendas or economic calculations as on attempts to improve quality of care. Family medicine practice styles in eastern Germany, for example, have changed radically in the transition to new political institutions. In some parts of North America, family physicians are increasingly associated with large hospital systems that have administrators who might not understand or value continuity of care.

Increases in specialization have led to changes in the scope of comprehensiveness for family physicians. Canadian family physicians, for example, are becoming less likely to deliver babies, give anesthetics, provide care in emergency departments and nursing homes, or make house calls. ${ }^{14}$ Other changes have expanded the role of the family physician, such as the recent recognition of the importance of primary care in provision of mental health in Bosnia. ${ }^{15}$

The methods of family medicine are also changing in response to the ongoing explosion in medical knowledge. Fortunately, this unprecedented growth has been accompanied by huge improvements in access to that knowledge through technologies, such as the Internet, and through the availability of careful systematic reviews, such as those provided by the Cochrane Collaboration. As a result, it has actually become easier for a properly trained family physician to access the latest evidence and to apply it to patient care.

\section{IMPLICATIONS FOR RESEARCH}

That opportunities to implement the core philosophy and style of family medicine differ across the world and are changing with time provides a rich opportunity for family medicine research. Hibbard and Nutting ${ }^{16}$ have suggested that "each perspective contributes compatible, but different, sets of research issues. Limiting the concept of primary care to a single perspective limits the ability to define the (relevant) research issues."

Whether each change of the sort we have noted is for better or for worse could serve as an important research question. To what extent is each a threat to the essential role of the family physician? How successful are family physicians in adapting to situations and changes in ways that improve health outcomes for their patients?

Complexity and variation have important implications for the methods needed for this research and for the role of community-based family physicians as participants in the research effort. Because of the scope of family medicine, with its simultaneous adoption of a patient's view and a view of the larger system, the scope of potential research questions is broad. Diversity in research methods becomes important when using, where appropriate, the whole range from randomized controlled trials to participatory research. Stange et 
a ${ }^{17}$ have provided a conceptual map that outlines the types of questions and methods that may be required. A recent study of American family physicians used direct observation of physician-patient encounters and has published multiple articles describing the findings. ${ }^{18}$ One such study using multiple methods showed that a group of US family physicians did not vary their care of patients based on the constraints imposed by differing insurance company coverage. ${ }^{19}$

Research is increasingly a collaborative effort, using research teams consisting of members who bring a variety of different perspectives and skills. Communitybased family physicians have important roles to play on the research team. Because community physicians are on the front line, adapting the family medicine philosophy to their local circumstances, they need help formulating the research questions - to describe their innovations in ways that allow for testing and research. Because the family medicine laboratory is the clinical setting, community physicians can serve a valuable role as members of a research network-collecting data in their practices to answer the important questions posed.

\section{CONCLUSIONS}

The core philosophy of family medicine includes the provision of primary care using a characteristic style of involvement with patients. The contexts in which individual physicians deliver care can have a major impact on their ability to practice in a way that reflects this core philosophy and style. Variety and change in these contexts provide fruitful opportunities for research.

These challenges, while demanding, make family medicine one of the most exciting settings for enquiry. Investigators must be clear about the underlying styles and resultant methods of family medicine within the system under study, especially when comparative research is being contemplated-whether it involves a single country or spans multiple health systems

There are major challenges to be faced in the research environment. In developed countries, there is a growing recognition of the need for a well-trained primary care-family medicine research workforce, but the research enterprise faces huge challenges from the laboratory and hospital health sciences, which take the largest share of the resources. Such a challenge can be met only by developing a highly skilled research workforce.

The challenge in fast-developing countries is different. Providing resources to get the research agenda moving, in terms of training, people, and money, is what is needed. There is a serious need for research knowledge exchange between countries, supported by the resources of the wealthier nations and sensitive to the cultural, contextual, and systems issues identified here.
To read or post commentaries in response to this article, see it online at http://www.annfammed.org/cgi/content/full/2/suppl_2/S41.

Key words: Family medicine; physicians, family; research; physicians' practice patterns; research priorities; research methods

A version of this paper was presented at the Wonca Research Conference, Kingston, Ontario, Canada, March 8-11, 2003.

Acknowledgments We thank all of our colleagues at the Wonca research meeting in Kingston, Ontario, who contributed to a discussion on a draft of this paper; in particular, we want to thank Ann Macaulay, Aziz Khan Tank, Giuseppe Maso, and Chris van Weel.

\section{References}

1. Horder J, Byrne P, Freeling P, Harris C, Irvine D, Marinker M, for the Working Party of the Royal College of General Practitioners. The Future General Practitioner- Learning and Teaching. London: RCGP; 1972.

2. McWhinney IR. A Textbook of Family Medicine. New York, NY: Oxford University Press; 1997.

3. Olesen F, Dickinson J, Hjortdahl P. General practice - time for a new definition. BMJ. 2000;320:354-357.

4. Stephen WJ. An Analysis Of Primary Medical Care: An International Study. Cambridge: Cambridge University Press; 1978.

5. WONCA. The Role of the General Practitioner/Family Physician in Health Care Systems. Victoria: WONCA; 1999.

6. Starfield B. Is primary care essential? Lancet. 1994;344:1129-1133.

7. Shi L, Starfield B. Income inequality, primary care, and health indicators. J Fam Pract. 1999;48:275-284.

8. Stewart M, Brown JB, Donner A, et al. The impact of patient-centered care on outcomes. J Fam Pract. 2000;49:796-804

9. Boerma WGW, Fleming DM. The Role of General Practice in Primary Health Care. London: The Stationary Office; 1998.

10. Fleming DM. The European Study of Referrals From Primary to Secondary Care. Amsterdam: Thesis Publishers; 1993.

11. Royal College of General Practitioners. Health and Prevention in Primary Care. Report from General Practice No. 18. London: Royal College of General Practitioners; 1981

12. Brown S, ed. Physician Funding And Health Care Systems-An International Perspective. London: Royal College of General Practitioners; 1999.

13. Committee on Quality of Health Care in America, Institute of Medicine. Crossing the Quality Chasm: A New Health System for the 21st Century. Washington, DC: National Academies Press; 2001.

14. Chan BT. The declining comprehensiveness of primary care. (MAJ. 2002;166:429-434.

15. Ceric I, Loga S, Sinanovic O, et al. Reconstruction of mental health services in Bosnia and Herzegovina. Med Arh. 2001;55(1 Suppl 1):5-23.

16. Hibbard $\mathrm{H}$, Nutting PA. Research in primary care: a national priority. In: Hibbard H, Nutting PA, Grady ML, eds. Primary Care Research: Theory and Methods. Washington, DC: US Department of Health and Human Services, Public Health Service, Agency for Health Care Policy and Research; 1991.

17. Stange KC, Miller WL, MCWhinney I. Developing the knowledge base of family medicine. Fam Med. 2001;33:286-297.

18. Stange KC, Zyzanski SJ, Jaen CR, et al. Illuminating the 'black box'. A description of 4454 patient visits to 138 family physicians. J Fam Pract. 1998;46:377-389.

19. Kikano GE, Snyder CW, Callahan EJ, Goodwin MA, Stange KC. A comparison of ambulatory services for patients with managed care and fee-for-service insurance. Am J Manag Care. 2002;8:181-186. 